\title{
Economic Value and Environmental Impact (EVEI) analysis of biorefinery
}

\section{systems}

\author{
Elias Martinez-Hernandez ${ }^{a}$, Grant Campbell ${ }^{b}$, Jhuma Sadhukhan $^{c, *}$ \\ ${ }^{a}$ Centre for Process Integration, University of Manchester, Manchester, M13 9PL, UK, \\ elias.martinezhernandez@manchester.ac.uk \\ ${ }^{b}$ Satake Centre for Grain Process Engineering, University of Manchester, Manchester, \\ M13 9PL, UK, grant.campbell@manchester.ac.uk \\ ${ }^{c}$ Centre for Environmental Strategy, University of Surrey, Guildford GU2 7XH, UK, \\ J.Sadhukhan@surrey.ac.uk
}

\begin{abstract}
The selection of product portfolios, processing routes and the combination of technologies to obtain a sustainable biorefinery design according to economic and environmental criteria represents a challenge to process engineering. The aim of this research is to generate a robust methodology that assists the process engineers to conceptually optimise the environmental and economic performances of biorefinery systems. A novel Economic Value and Environmental Impact analysis (EVEI) methodology is presented in this paper. The EVEI analysis is a tool that emerges from the combination of the value analysis method for the evaluation of economic potential with environmental footprinting for impact analysis. The methodology has been effectively demonstrated by providing insights into the performances of a bioethanol plant as a case study. The systematisation of the methodology allowed its implementation and integration into a Computer-Aided Process Engineering (CAPE) tool in the spreadsheet environment.

Keywords: biorefinery, sustainable design, value analysis, environmental impact analysis, LCA
\end{abstract}


* Corresponding author. Tel.: +44 148368 6642, Fax: +44 1483686671.

\section{Introduction}

Biorefinery systems have emerged as an attractive way for energy generation, in the form of combined heat and power (CHP) and biofuels, alongside chemical production, with great promise for reduced environmental impact, allowing the shift from a economy based on fossil feedstocks to a biomass-based sourcing of renewable energy and materials in a progressive manner (Kamm and Kamm, 2005; Cherubini, 2009). The global potential biorefinery market throughout the entire biomass value chain has been projected as $\$ 295$ billion by 2020 (King, 2010). This estimate includes biorefinery products that could replace fossil-based products that are chemically identical (e.g. ethylene from bioethanol can replace ethylene from natural gas) and those that could substitute for products having similar functionality (e.g. polylactic acid can substitute polyethylene terephtalate used for plastic bottles). The biorefinery concept has been practised widely in the corn wet mill industry, the pulp and paper industry and, more recently, the biofuel industry through the expansion of their product portfolios with value added products in search for improved process economics and environmental sustainability (Lynd et al., 2005; Janssen, 2012). To benefit from these advantages, biorefineries must be designed and assessed all the way from factory boundary to system cradle-to-grave in an integrated manner.

Process integration and mathematical optimisation techniques have been applied to handle the complexity of the product allocation problem for biorefineries in terms of economic and environmental impact by Sammons et al. (2008). They proposed an optimisation framework that enabled the inclusion of profitability and other technoeconomic metrics to screen in an initial stage those alternatives that maximize profitability. In a second stage, the solutions are assessed using environmental metrics. 
Sharma et al. (2011) have considered a robust and flexible MILP financial planning model to maximize value for a multi-product multiplatform biorefinery enterprise including a weighting function for tracking the effect of process integration on the $\mathrm{CO}_{2}$ emissions of the final biorefinery configuration. Tan et al. (2009) proposed an LCAbased modelling framework for fuzzy multi-objective optimisation of three footprint metrics - land use, water and carbon. An LCA-based sustainability multi-scale multimethod approach was applied for integrated assessment of material, embodied energy, environmental impact and economic flows and performance by Fahd et al. (2012). A systematic methodology for the design and analysis with respect to cost, operation and sustainability to generate new alternatives with respect to wastewater reduction and efficient downstream separation was proposed by Alvarado-Morales et al. (2009). An approach combining exergy, life cycle and economic analyses was performed for sustainable biofuel production using Aspen Plus ${ }^{\mathrm{TM}}$ software by Ojeda et al. (2011). A shortcut method for the synthesis and screening of integrated biorefineries was developed by Bao et al. (2011), wherein a structural representation of chemical species and conversion operator was developed to track individual chemicals allowing for the processing of multiple chemicals in processing technologies. Heyne and Harvey (2012) used the Energy Price and Carbon Balance Scenarios (ENPAC) for comparison of thermodynamic, economic and carbon footprint performances of biorefinery systems. A multi-objective static optimisation framework that included both economical and environmental performance objectives for sustainable biofuel supply chains was proposed by Akgul et al. (2012) to have a complete view of the future implications of biorefinery systems. The various approaches above show how biorefinery assessments have moved from the sole use of techno-economic measures to the inclusion of sustainability metrics useful for decision making in biorefinery design and planning. 
The acquisition of measures and of correlations between them in a dynamic manner across the scales is not a trivial task, as it requires applying the sustainability indicators into the design practice (Azapagic and Clift, 1999a and 1999b). As the complexity of the transition from fossil to renewable feedstock arises with more competitive products, processes and technologies, the development of sustainability indicators has led to a list of priorities based on the objectives for such a transition tackling the global climate change, scarcity of fossil resources and sustainable development. As a result, GHG emissions reduction, fossil energy saving and economic potential of biorefinery products have become important measures that make a biorefinery a plausible alternative to crude oil refineries (Brehmer et al, 2009; Fahd et al, 2012).

Although there have been a number of papers published in the area of biorefinery process design, integration and sustainability indicators, no differential environmental impact analysis of the smallest element (such as a stream associated with a unit operation) to the largest element (such as a whole system) has been proposed so far by means of a unified framework. With the awareness of the significance of integration of sustainability indicators in biorefinery design, there are clear and strengthening imperatives for combining differential economic and environmental emission saving marginal analyses across the scales linking process to systems level variables and design objectives. To this end, this paper presents a robust biorefinery systems analysis tool based on a methodology that combines the concepts of economic value and environmental impact (EVEI) analysis. The marginal economic and environmental impact saving obtained from the products are used as indicators to determine whether a biorefinery system is more sustainable than its fossil-based counterpart system. The methodology adapts environmental impact (EI) analysis 
techniques (such as life cycle assessment, LCA) to the value analysis methodology (Sadhukhan et al., 2003, 2004, 2008) while extending the differential analysis of network elements (i.e. streams, paths and trees) from the latter methodology to perform EI analysis. This integrated approach allows decision making regarding environmental and economic considerations at the same time, in order to achieve a sustainable biorefinery design. Section 2 presents methodological aspects of the tool. The tool is then applied to assess a wheat biorefinery system in Section 3.

\section{The EVEI analysis methodology}

\section{Economic and environmental impact concepts}

The main variables in the EVEI analysis are the economic and EI costs and values. The costs of feedstock $\left(C_{f}\right)$, auxiliary raw materials $\left(C_{a}\right)$ and utilities $\left(C_{u}\right)$ correspond to their market prices or production costs when produced on site. The EI "cost" is the embodied impact incurred during the production and transportation of materials or energy carriers. The end product economic values can be their market prices $\left(V_{p}\right)$. The EI credit $\left(D_{p}\right)$ of a biorefinery product is obtained from the displacement of an equivalent fossil-based product. $D_{p}$ is a product of the EI cost of the equivalent fossil-based product $\left(I_{p e q}\right)$ and an equivalency factor $\beta$, the amount of fossilbased product displaced per unit amount of the biorefinery product, provided by the relationship in Eq. 1.

$$
D_{p}=\beta \times I_{p e q}
$$

The concept of credit value, or $D_{p}$, indicates the upper bound or limit for the EI cost of a biorefinery product in order to be environmentally advantageous over the fossil counterpart. Subtracting the EI cost from $D_{p}$ of a biorefinery product yields its EI reduction potential with respect to the equivalent fossil-based product. The resulting EI reduction is termed as EI saving margin, a concept equivalent to economic margin. 
Fig. 1 presents the variables used to evaluate the economics and the corresponding variables to evaluate EI of a generic processing element (e.g. a process unit or a path or a tree or a whole biorefinery system). This correspondence clarifies the basis for the systematisation of a combined economic value and environmental impact analysis that is a function of the process operation variables and of externalities such as feedstock and product market prices and embodied EI.

\section{Fig. 1}

The economic cost of a material or energy carrier refers to the cost of producing one unit of the mass or energy carrier. There is an EI cost incurred from its production known as the "embodied" EI. The adoption of a life cycle approach to determine embodied EI allows the analysis to be carried out in a systematic and holistic way as required for biorefinery systems. The aggregated results from any of the various EI categories (climate change, acidification, eutrophication, human toxicity, etc.) can be used as indicators according to the goal set for the EVEI analysis. Greenhouse gas (GHG) emissions accounted for climate change category (as $\mathrm{CO}_{2}$-eq) is used as the main environmental performance indicator due to its relevance to biofuels which face stricter policies imposed in several countries in order to be considered as sustainable (European Union, 2009). Thus, the marginal savings in GHG emissions from the biorefinery products works as an accepted and practical sustainability indicator. This saving may be certified and traded by the biorefinery in the carbon credit stock market. For consistency, the functional units for economic and EI variables are $1 \mathrm{~kg}$ of material streams or $1 \mathrm{MJ}$ of energy streams under consideration.

Due to variability in biomass resources and production systems, a typical embodied factor might not represent the actual EI cost of a feedstock $\left(I_{f}\right)$. To determine $I_{f}$, it is recommended to include the feedstock production within the system boundary 
and integrate it to the modelling. In this way, important factors affecting biomass yield and properties (e.g. nitrogen fertilisation, rainfall) can be included to track their impact on $I_{f}$ and the overall results. The selection of boundaries is of high relevance to determine EI cost of biomass feedstock and EI credit value of products. Depending on the boundary, the EI cost of the biomass feedstock or EI credit value of a biorefinery product may be composed by several factors. Ideally, the system must be analysed using a cradle-to-grave approach. When using such an approach, $I_{f}$ is made up of $\mathrm{CO}_{2}$ binding from photosynthesis $\left(B_{f}\right)$, EI from transportation $\left(T_{f}\right)$ and EI from production $\left(G_{f}\right)$ as in Eq. 2.

$$
I_{f}=G_{f}+T_{f}-B_{f}
$$

The concepts of EI cost of auxiliary raw materials $\left(I_{a}\right)$ and utilities $\left(I_{u}\right)$ are used to express their embodied environmental impact from production, which can be derived from the embodied impacts reported in LCA databases such as SimaPro ${ }^{\circledR}, \mathrm{Gabi}^{\circledR}$, Ecoinvent $^{\circledR}$, etc. (Rice et al., 1997; Frischknecht and Rebitzer, 2005). When produced on-site, the EI cost can be calculated from the system models. The EI cost estimation should be dynamic and determined in spatial and temporal domains. A differentiation between marketable products and emission/waste streams should be done as the latter type of stream needs to be treated, incinerated or sent to landfill and thus adds to the emission impact cost $\left(I_{m}\right)$. The emission impact cost, $I_{m}$, of an emission/waste stream is calculated from its composition and components' characterisation factors under the EI category being evaluated, or from EI generated during treatment or disposal. Similarly, the payment for emissions control and treatment or disposal of waste streams adds to a corresponding emission economic cost $\left(C_{m}\right)$. Then, these costs must be allocated amongst the main process streams and then to the end products, as shown later. 
The operating costs $(O)$ of a process unit consist of the costs of utilities, and the disposal or treatment cost of any emission/waste stream produced. The impact of emissions or wastes $\left(I_{m}\right)$ is taken into account in the operating impact cost $(I O)$. In addition, an annualised capital cost $(C C)$ using the discounted cash flow calculation over a biorefinery plant lifetime can be included in $O$ (Sadhukhan et al., 2008). The impact from the construction materials is estimated from the preliminary equipment sizing and can be linearly distributed over the biorefinery lifetime and included in $I O$ as an annualised EI cost of construction $(C I)$. With the variables defined above, it is possible to make a vector representation of the total unit costs for a process unit $k$ as in Eq. 3.

$$
\bar{O}_{k}(X)=\left[\begin{array}{c}
O_{k} \\
I O_{k}
\end{array}\right]=\left[\begin{array}{c}
\bar{C}_{a, k} \\
\bar{I}_{a, k}
\end{array}\right] \times \bar{A}_{k}+\left[\begin{array}{c}
\bar{C}_{u, k} \\
\bar{I}_{u, k}
\end{array}\right] \times \bar{U}_{k}+\left[\begin{array}{c}
\bar{C}_{m, k} \\
\bar{I}_{m, k}
\end{array}\right] \times \bar{M}_{k}+\left[\begin{array}{c}
C C_{k} \\
C I_{k}
\end{array}\right]
$$

$\bar{O}_{k}(X)$ denotes unit costs as function of process variables $(X) . \bar{A}_{k}, \bar{U}_{k}$ and $\bar{M}_{k}$ represents a one column vector with the flow rates of auxiliary raw materials, utilities and emissions/wastes, respectively. $\bar{C}_{a, k}, \bar{C}_{u, k}$ and $\bar{C}_{m, k}$ represents a one row vector containing the corresponding economic costs whilst $\bar{I}_{a, k}, \bar{I}_{u, k}$ and $\bar{I}_{m, k}$ is a one row vector containing the respective EI costs. The inclusion of the costs from emissions and auxiliary raw materials into the total unit costs allows their allocation among the main process streams and propagation towards the end products.

\section{Modeling of streams}

The economic and environmental variables are correlated to the mass and energy balance analysis obtained and thereby to the process design variables. Thus, the process design variables are linked to the economic and environmental impact modelling of a stream or a unit and an entire process network. The economic and EI properties for 
process streams are represented by their value on processing (VOP), impact credit value on processing (CVP), cost of production (COP) and impact cost of production (ICP). The modelling of the streams starts with the known values for feedstock costs and product values. For a biorefinery product, $\mathrm{VOP}=V_{p}$ and $\mathrm{CVP}=D_{p}$. For a feedstock, $\mathrm{COP}=C_{f}$ and $\mathrm{ICP}=I_{f}$. After the establishment of these equivalencies, it is possible to generalise the modelling of economic and EI costs and values.

Consider $\bar{V}$ as a vector containing the "values" (VOP and CVP) of a feed $f$ to a process unit $k$. The vector $\bar{V}$ can be calculated from the known values of the product streams $p$ and the total unit costs $\bar{O}_{k}(X)$ through Eq. 4, where $q$ is the number of products (excluding emissions/wastes) and $g$ is the number of feedstock considered as main material streams (excluding auxiliary raw materials). $F_{f}$ denotes flow rate of feedstocks to the unit and $P_{p}$ denotes flow rate of products from the unit.

$$
\bar{V}_{f}=\left[\sum_{p=1}^{q} \bar{V}_{p} P_{p}-\bar{O}_{k}(X)\right] / \sum_{f=1}^{g} F_{f}
$$

To determine the costs of streams (COP and ICP) the cost of the process units must be allocated amongst their outlet or product streams. Allocation of impacts at a global system level is common practice in LCA. However, the evaluation of allocation factors at intermediate level in the method presented here decreases the complexity of the allocation problem. Rather than allocating impacts to all the end products in a system, at elementary level (unit operation) the number of products is commonly reduced to two (flash) or three (tri-phase separator). This also avoids allocating impacts to products from certain unit operations from which they are not derived at all (e.g. ethanol in a bioethanol plant is not derived from the rotary dryer used to produce DDGS). Therefore, in this method the economic and EI costs from the unit operations that are used for 
recovery, refining or conditioning of a particular product (e.g. bioethanol purification, DDGS drying) are attributed exclusively to that product. By implementing this differentiation, the environmental impact values calculated from this method more closely reflect what is happening in the system and can provide more useful insights.

Any of the allocation methods such as, mass or energy allocation and system expansion (Heijungs and Frischknecht, 1998; Azapagic and Clift, 1999c; Kim and Dale, 2002; Dalgaard et al., 2008) could be used in EVEI analysis. However, allocation by economic value at process unit level is adopted for consistency and practical reasons. The economic value is regarded as a good indicator for impact allocation since it reflects the worth of a product in a real economy. Another reason is that the VOP of intermediate streams can be readily calculated to capture market variability. Furthermore, the resulting allocation factor $(\alpha)$ is a direct function of process models. This feature allows capturing the interactions at the different system levels. The allocation factor of a product stream $\left(\alpha_{p}\right)$ from a multiproduct unit is determined by using Eq. 5.

$$
\alpha_{p}=\operatorname{VOP}_{p} P_{p} / \sum_{p=1}^{q} \operatorname{VOP}_{p} P_{p}
$$

Consider now $\bar{C}$ as a vector containing the "costs" (COP and ICP) of a product $p$ from a process unit $k . \bar{C}$ can be predicted for a product stream $p$ from the known costs of the feed streams $f$ and the total unit costs $\bar{O}_{k}(X)$ through Eq. 6.

$$
\bar{C}_{p}=\left[\sum_{f=1}^{g} \bar{C}_{f} F_{f}+\bar{O}_{k}(X)\right] \alpha_{p} / P_{p}
$$

The difference between $\bar{V}$ and $\bar{C}$ of a stream provides the margins $(\Delta)$ that indicate its potential economic profit $(\Delta e=\mathrm{VOP}-\mathrm{COP})$ and environmental impact saving 
$(\Delta i=\mathrm{CVP}-\mathrm{ICP})$ from production. The costs and values of the streams plotted against its mass flow rate is a graphic representation of the stream economic profile and the stream environmental profile as shown in Fig. 2. Two generic streams (S1 and S2) are presented in this figure for illustration purposes. In the stream economic profile, the area enclosed between VOP and COP is equal to the economic margin $\Delta e$ multiplied by the stream flow rate and represents the total profit from the stream production. The condition for a stream to be profitable is that the VOP line is above the COP line, i.e VOP>COP (Sadhukhan et al., 2003, 2004, 2008). This results in a positive area as shown for stream S1 in Fig. 2a. A non-profitable stream would produce an economic profile similar to stream $\mathrm{S} 2$.

Analogously, in the stream environmental profile, the area enclosed between CVP and ICP is equal to the EI savings margin $\Delta i$ multiplied by the stream flow rate and represents the total EI savings from the stream production. The condition for a stream to be sustainable is that the CVP line is above the ICP line, i.e. CVP>ICP, the impact credit value on (further) processing is greater than the "impact cost" of production so far. This is illustrated for stream S2 in Fig. 2b. A stream is non-sustainable when the opposite occurs, as shown in the environmental profile for stream S1. Notice that the streams used for illustration exemplify two extreme cases where a stream is profitable but non-sustainable and vice versa. Thus, the trade-offs can be easily recognised from the stream profiles.

\section{Fig. 2}

The environmental and economic performance of a biorefinery can be evaluated from the marketable product streams. The margins of the biorefinery products contain the value generated throughout their production pathways in the process network minus the cumulative and allocated costs incurred during production. Thus, the sum of the 
product margins provides the total margins of a biorefinery as shown in Eq. 7 and 8; where $n$ is the number of biorefinery products and $P_{b p}$ the mass flow rate of the biorefinery product $b p$. For instance, this sum is also equal to the total margins obtained from the feedstocks since their values result from the values of their corresponding end products minus the costs incurred by their processing. This fact indicates that the variability in market prices and in biomass properties and the interactions between the different processing elements (process units, paths and trees) are as readily captured within the product margins as in the biomass feedstock margin, providing robustness to the EVEI analysis methodology.

$$
\begin{aligned}
& \text { Biorefinery economic margin }=\sum_{b p=1}^{n}(\Delta e)_{b p} P_{b p} \\
& \text { Biorefinery EI saving margin }=\sum_{b p=1}^{n}(\Delta i)_{b p} P_{b p}
\end{aligned}
$$

The modelling of the streams to determine the biorefinery margins can also be helpful when comparing pathway alternatives. When two or more alternatives for the processing of a stream are evaluated (e.g. vegetable oil for biodiesel or green diesel) the trade-offs between their performance indicators $(\Delta e$ and $\Delta i)$ can be easily recognised. This alternative screening feature of the EVEI analysis method can be exploited to select processing routes that provide biorefinery profitability without compromising the environment, leading to a sustainable biorefinery design. Another utility of the stream margins concept is that the relative percentage of EI saving $\left(s_{p}\right)$ of a biorefinery product with respect to a fossil-based product can be easily calculated using Eq. 9. This is particularly useful when evaluating the GHG emissions from the life cycle of biofuel production, as shown later in the case study. 


$$
s_{p}=\frac{(\Delta i)_{p}}{\left(I_{p e q} \times \beta\right)_{p}} \times 100
$$

Once the fundamentals of the EVEI analysis have been established, the algorithms presented above can be used for the modelling of process paths, trees and entire biorefinery processing networks. Strategic methodologies can be developed depending on the objective of the analysis, e.g. new process design, process integration, biorefinery expansion or optimisation.

\section{Case study}

A biorefinery based in the UK producing bioethanol and DDGS from wheat grain is represented in Fig. 3. The biorefinery system is analysed using the EVEI analysis methodology to determine the sustainability of bioethanol fuel production according to the target for GHG emissions savings set by the EU directive (European Union, 2009). Thus, the EI variables of the streams are determined as amount of $\mathrm{CO}_{2}$ equivalents $\left(\mathrm{CO}_{2}\right.$-eq) per unit of mass (i.e. in $\left.\mathrm{kg} \mathrm{kg}^{-1}\right)$. Capital costs and $\mathrm{EI}$ from construction and transportation were not considered in this case study. The calculation basis is a biorefinery processing $1200 \mathrm{kt} \mathrm{y}^{-1}\left(1 \mathrm{kt}=1 \times 10^{6} \mathrm{~kg}\right)$ of wheat. Modelling of wheat production and the bioethanol process as well as economic and EI data have been adopted from Williams et al. (2006) and Sadhukhan et al. (2008).

\section{Fig. 3}

A cradle-to-grave approach is considered to determine EI cost of feedstock and credit value of products. The allocated EI cost of wheat production from LCA modelling under UK conditions was $0.492 \mathrm{~kg} \mathrm{~kg}^{-1}$ whilst the $\mathrm{CO}_{2}$ binding corresponding to grain (excluding the straw fraction being harvested) has been reported 
as $1.1 \mathrm{~kg} \mathrm{~kg}^{-1}$ (Küsters, 2009). Using Eq. 2 and neglecting EI from transportation, the EI cost of feedstock is: $I_{f l}=0.492-1.1=-0.61 \mathrm{~kg} \mathrm{~kg}^{-1}$. The credit values of products are calculated for $p l=$ bioethanol and $p 2=$ DDGS. Since bioethanol $\left(\mathrm{HV}=26.7 \mathrm{MJ} \mathrm{kg}^{-1}\right)$ is a biofuel substitute for gasoline $\left(\mathrm{HV}=44.5 \mathrm{MJ} \mathrm{kg}^{-1}, I_{p e q}=3.8 \mathrm{~kg} \mathrm{~kg}^{-1}\right)$, the equivalency ratio is found to be $\beta=0.6 \mathrm{~kg} \mathrm{~kg}^{-1}$, assuming the same fuel efficiency. Considering that $\mathrm{CO}_{2}$ is the only GHG generated from ethanol combustion, the EI credit value is determined using Eq. 1 as $D_{p 1}=3.8 \times 0.6-2 \times 44.01 / 46.07=0.33 \mathrm{~kg} \mathrm{~kg}^{-1}$. Assuming that $1 \mathrm{~kg}$ of DDGS is equivalent to $0.8 \mathrm{~kg}$ of soy meal according to protein content comparisons (Dalgaard et al., 2008) and using the EI cost of soy meal of 0.726 $\mathrm{kg} \mathrm{kg}^{-1}$ (Kim and Dale, 2002), the equivalency ratio for DDGS is $\beta=0.8 \mathrm{~kg} \mathrm{~kg}^{-1}$ and the EI credit value $D_{p 2}=0.8 \times 0.726=0.581 \mathrm{~kg} \mathrm{~kg}^{-1}$.

The costs for each process unit are summarised in Table 1. The liquefaction (LIQ-1) and the ethanol recovery units are the main contributors to economic costs with $56.7 \%$ and $17.2 \%$ of the total, respectively. $60 \%$ of the total economic operating costs come from auxiliary raw materials and $40 \%$ from utilities. Regarding EI costs, the fermentation and ethanol recovery units are the main hot spots contributing with $65.5 \%$ and $14.0 \%$ of the total, respectively. In this case, the total EI costs come from the emissions release during fermentation (64.8\%), utilities (30.1\%) and auxiliary raw materials $(5.1 \%)$.

\section{Table 1}

By using the unit costs from Table 1 and data for feedstock and products calculated above, the EVEI calculations can be performed. Table 2 presents the EVEI calculations for the streams around the units CFG-1 and REC-1 (Fig. 3). Notice that calculation starts with the prediction of $\bar{V}$ through a backward calculation procedure, 
while $\bar{C}$ is predicted following a forward calculation procedure. This is similar to the way that critical paths are calculated in critical path planning. This is also the natural sequence since VOP of product streams must be known in advance to determine the EI allocation factor $\alpha$. The allocation factors were found to be 0.9268 for the stream going to the bioethanol recovery and 0.0732 for the stream going to the rotary dryer.

\section{Table 2}

The systematisation of the methodology allowed its integration into a computeraided process engineering (CAPE) tool developed for this purpose in the Excel-VBA platform using an object oriented approach. The software tool includes LCA modelling for feedstock production, biorefinery process simulation and EVEI analysis calculations. The integrated tool was used to calculate all the EVEI variables for the streams in the biorefinery. Fig. 3 is a screenshot of the software showing the biorefinery flowsheet and EVEI calculation results.

Fig. 4 shows the economic and EI profiles for all streams in the biorefinery case study. By plotting all the main process streams in a path or tree, the evolution of the costs, values and margins throughout the process network can be easily visualised. The area of the feedstock profile or the total area of the products indicates the corresponding economic and EI saving margins of the biorefinery. From the economic profile it can be seen that the VOP line always remains above the COP line, indicating all main streams are profitable. Notice how a stream with low economic margin like f1-2-3-4-5-7 $\left(\Delta e=11.3 \mathrm{f} \mathrm{t}^{-1}\right)$, containing the wet solids, is converted into a stream with higher economic margin (DDGS, $\Delta e=29.2 \mathfrak{t}^{-1}$ ) when is further processed in the rotary dryer (RDY-1, unit 7). The gross economic potential of the biorefinery determined from Eq. 7 or from the total areas from the product streams in Fig. $4 a$ is $118 \mathrm{M}^{-1}$. 


\section{Fig. 4}

From the environmental profile, it can be seen that impact cost of production, ICP, remains negative for the tree with the pathway producing bioethanol because of the propagation of the negative EI cost from the biomass feedstock. In the DDGS pathway, a shift in ICP from negative to positive occurs after the stream f1-2-3-4-5-7 is processed in the rotary dryer (Fig. 3). This means that the propagated negative EI cost of feedstock has been offset by the cumulative operating costs in this pathway. On the other hand, a shift in the EI credit value on processing (CVP) from positive (stream f1-2-3-4-5) to negative (stream f1-2-3-4), is produced after the fermentation unit (Fig. 3). This means that, at this point, the EI credits gained by the biorefinery products have been offset by the operating EI costs of the fermentation and downstream units. However, $\Delta i$ remains positive due to the propagation of the negative EI cost of feedstock conveyed in ICP. These insights obtained from the stream profiles provide a better picture of the environmental performance of the processing elements in a biorefinery system. The potential EI margin savings from the biorefinery products is $426.8 \mathrm{kt} \mathrm{y}^{-1}$ of $\mathrm{CO}_{2}$-eq. That is around $3620 \mathrm{t} \mathrm{M}^{-1}$ of $\mathrm{CO}_{2}$-eq. By considering the total operating costs plus the cost of wheat (141.6 $\left.\mathrm{M}^{-1}\right)$, the operating GHG mitigation costs results in $331.7 £ \mathrm{t}^{-1}$. By using Eq. 9 and results in Fig. 3, the relative GHG emissions savings from bioethanol with respect to gasoline is $31 \%$ and from DDGS with respect to soy meal is $83 \%$. The target according to the current EU policy for a biofuel to be sustainable is 35\% GHG savings (European Union, 2009). This means that the bioethanol fuel produced in the biorefinery under study might not be approved under this policy and alternatives for system improvement must be analysed before implementation.

From the hot spots identified in the system and the surplus of EI saving from DDGS, several options are available. One option is carbon capture and storage, which 
would compromise economic profitability due to its high costs. Another option is the use of DDGS as fuel to produce heat for ethanol recovery. The balance between $\mathrm{CO}_{2}$ generated from DDGS combustion and that saved from utilities must be positive. There is also an economic trade-off since the use of DDGS as fuel would imply fewer revenues from its production. The EVEI analysis would allow evaluation of the tradeoffs that appear in every alternative and select the best option in a systematic, insightful way.

\section{Conclusions}

The EVEI analysis methodology presented proved to be useful in providing insights into the economic and environmental performance of a biorefinery system. The analogies between economic and EI concepts allow the robust manipulation of both sets of variables. The economic and EI models can be integrated into process models, throwing light on the issues of non-linearity of the production function and allocation problem not addressed by the common EI analysis methods. The systematisation allowed the implementation of the methodology as a CAPE tool in Excel-VBA platform for easy deployment, available at http://biorefinerydesign.webs.com.

\section{Acknowledgements}

The authors are grateful for the financial support from the National Council of Science and Technology (CONACYT) of Mexico to undertake this work.

\section{References}

Akgul, O., Shah, N., Papageorgiou, L.G., 2012. An optimisation framework for a hybrid first/second generation bioethanol supply chain. Comput. Chem. Eng. 42, $101-114$. 
Alvarado-Morales, M., Terra, J., Gernaey, K.V., Woodley, J.M., Gani, R., 2009. Biorefining: Computer aided tools for sustainable design and analysis of bioethanol production. Chem. Eng. Res. Des. 87(9), 117-183.

Azapagic, A., Clift, R., 1999a. The application of life cycle assessment to process optimisation. Comput. Chem. Eng. 23(10), 1509-1526.

Azapagic, A., Clift, R., 1999b. Life cycle assessment and multiobjective optimisation. J. Clean. Product. 7(2), 135-143.

Azapagic, A., Clift, R., 1999c. Allocation of environmental burdens in multiplefunction systems. J. Clean. Product. 7(2), 101-119.

Bao, B., Ng, D.K.S., Tay, D.H.S., Jiménez-Gutiérrez, A., El-Halwagi, M.M., 2011. A shortcut method for the preliminary synthesis of process-technology pathways: An optimization approach and application for the conceptual design of integrated biorefineries. Comput. Chem. Eng. 35(8), 1374-1383.

Brehmer, B., Boom, R.M., Sanders, J., 2009. Maximum fossil fuel feedstock replacement potential of petrochemicals via biorefineries. Chem. Eng. Res. and Des. $87,1103-1119$.

Cherubini, F., Jungmeier, G., Wellisch, M., Willke, T., Skiadas, I., Van Ree, R., Jong, E., 2009. Toward a common classification approach for biorefinery systems. Biofuel Bioprod. Bior. 3, 534-546.

Dalgaard, R., Schmidt, J., Halberg, N., Christensen, P., Thrane, M., Pengue, W.A., 2008. LCA of soybean meal. Int. J. LCA 13(3), 240-254.

European Union, 2009. Directive 2009/28/EC of the European Parliament and of the Council of 23 April on the promotion of the use of energy from renewable sources and amending and subsequently repealing Directives 2001/77/EC and 2003/30/EC. 
Fahd, S., Fiorentino, G., Mellino, S., Ulgiati, S., 2012. Cropping bioenergy and biomaterials in marginal land: The added value of the biorefinery concept. Energy 37(1), 79-93.

Frischknecht, R., Rebitzer, G., 2005. The ecoinvent database system: a comprehensive web-based LCA database. J. Clean. Prod. 13, 1337-1343.

Heijungs, R., Frischknecht, R., 1998. A special view on the nature of the allocation problem. Int. J. LCA 3(5), 321-332.

Heyne, S., Harvey, S., 2012. Assessment of the energy and economic performance of second generation biofuel production processes using energy market scenarios. Appl. Energy, In Press, http://dx.doi.org/10.1016/j.apenergy.2012.03.034.

Janssen, M., 2012. Market potential of biorefinery products. In: Sanden B, editor. Systems perspectives on biorefineries. Chalmers University of Technology, Göteborg (Sweden), pp. 26-35.

Kamm, B., Kamm, M., 2005. Principles of biorefineries. Appl. Microbiol. Biotechnol. 64, 137-145.

Kim, S., Dale, B.E., 2002. Allocation procedure in ethanol production system from corn grain I. System expansion. Int. J. LCA. 4, 237-243.

King, D., 2010. The Future of Industrial Biorefineries. World Economic Forum, Switzerland. Available at: http://www3.weforum.org/docs/WEF_FutureIndustrialBiorefineries_Report_2010 .pdf.

Küsters, J., 2009. Energy and $\mathrm{CO}_{2}$ balance of bioenergy plants and of various forms of bio energy. International Symposium on Nutrient Management and Nutrient Demand of Energy Plants, July 07-08, Budapest, Hungary. International Potash Institute, Horgen, Switzerland. Available at: www.ipipotash.org. 
Lynd, L.R., Wyman, C., Laser, M., Johnson, D., Landucci, R., 2005. Strategic

Biorefinery Analysis: Review of Existing Biorefinery Examples. NREL, Golden, CO, USA. Available at http://www.nrel.gov/docs/fy06osti/34895.pdf.

Ojeda, K., Ávila, O., Suárez, J., Kafarov, V., 2011. Evaluation of technological alternatives for process integration of sugarcane bagasse for sustainable biofuels production-Part 1. Chem. Eng. Res.and Des. 89(3), 270-279.

Rice, G., Clift, R., Burns, R., 1997. Comparison of currently available European LCA software. Int. J. LCA 2(1), 53-59.

Sadhukhan, J., Mustafa, M.A., Misailidis, N., Mateos-Salvador, F., Du, C., Campbell, G.M., 2008. Value analysis tool for feasibility studies of biorefineries integrated with value added production. Chem. Eng. Sci. 63, 503-519.

Sadhukhan, J., Zhang N., Zhu, X.X., 2004. Analytical optimisation of industrial systems and applications to refineries, petrochemicals. Chem. Eng. Sci. 59, 41694192.

Sadhukhan, J., Zhang, N., Zhu, X.X., 2003. Value analysis of complex systems and industrial applications to refineries. Ind. Eng. Chem. Res. 42(21), 5165-5181.

Sammons Jr., N.E., Yuan, W., Eden, M.R., Aksoy, B., Cullinan, H.T., 2008. Optimal biorefinery product allocation by combining process and economic modeling. Chem. Eng. Res. Des. 86(7), 800-808.

Sharma, P., Sarker, B.R., Romagnoli, J.A., 2011. A decision support tool for strategic planning of sustainable biorefineries. Comput. Chem. Eng. 35(9), 1767-1781

Tan, R.R., Ballacillo, J.B., Aviso, K.B., Culaba, A.B., 2009. A fuzzy multiple-objective approach to the optimization of bioenergy system footprints. Chem. Eng. Res.and Des. $87,1162-1170$. 
Williams, A.G., Audsley, E., Sandars, D.L., 2006. Determining the environmental burdens and resource use in the production of agricultural and horticultural commodities. Cranfield University and DEFRA, Bedford, UK. 


\section{FIGURE CAPTIONS}

Fig. 1 Equivalency between the economic and EI variables used in the EVEI analysis methodology.

Fig. 2 Economic (a) and environmental (b) profiles for generic streams S1 and S2.

Fig. 3 EVEI analysis results of a wheat-based biorefinery.

Fig. 4 Economic (a) and environmental (b) profiles of the wheat-based biorefinery system. 


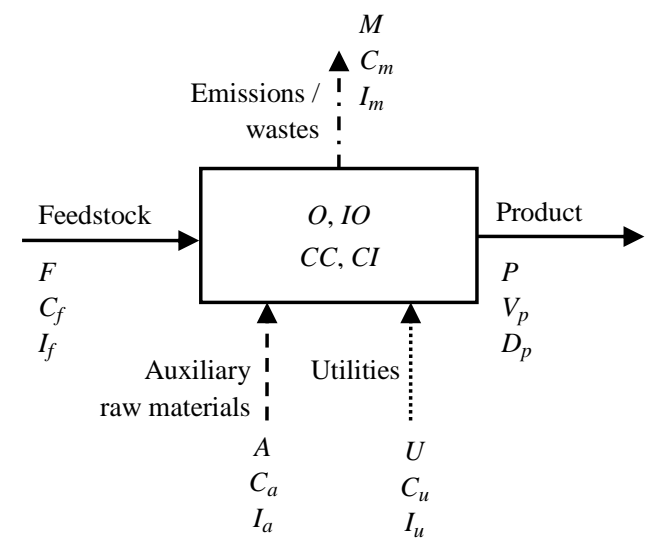

Economic variables

$C_{f} \quad$ cost offeedstock

EI variables

$V_{p} \quad$ price of product

$I_{f} \quad$ EI from feedstock

$O \quad$ operating cost of unit

$D_{p} \quad$ EI credit of product

$C C$ annualised capital cost of unit

IO EI from unit operation

$C_{a} \quad$ cost of auxiliary raw materials

$C_{u} \quad$ cost of utilities

CI annualised EI from construction

$C_{m} \quad$ disposal/treatment cost

$I_{a} \quad$ EI from auxiliary raw materials

$I_{u} \quad$ EI from utilities

$I_{m} \quad$ EI of emission / waste

$F \quad$ feedstock flow rate

Flow rate variables

$P \quad$ product flow rate

A Auxiliary raw material flow rate

$U$ utility consumption rate

M emission / waste flow rate

\section{Fig. 5}




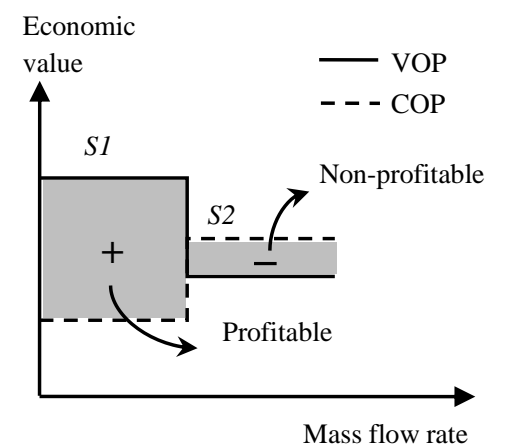

(a)

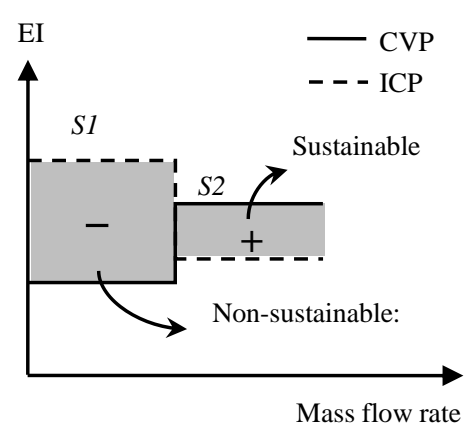

(b)

Fig. 6 


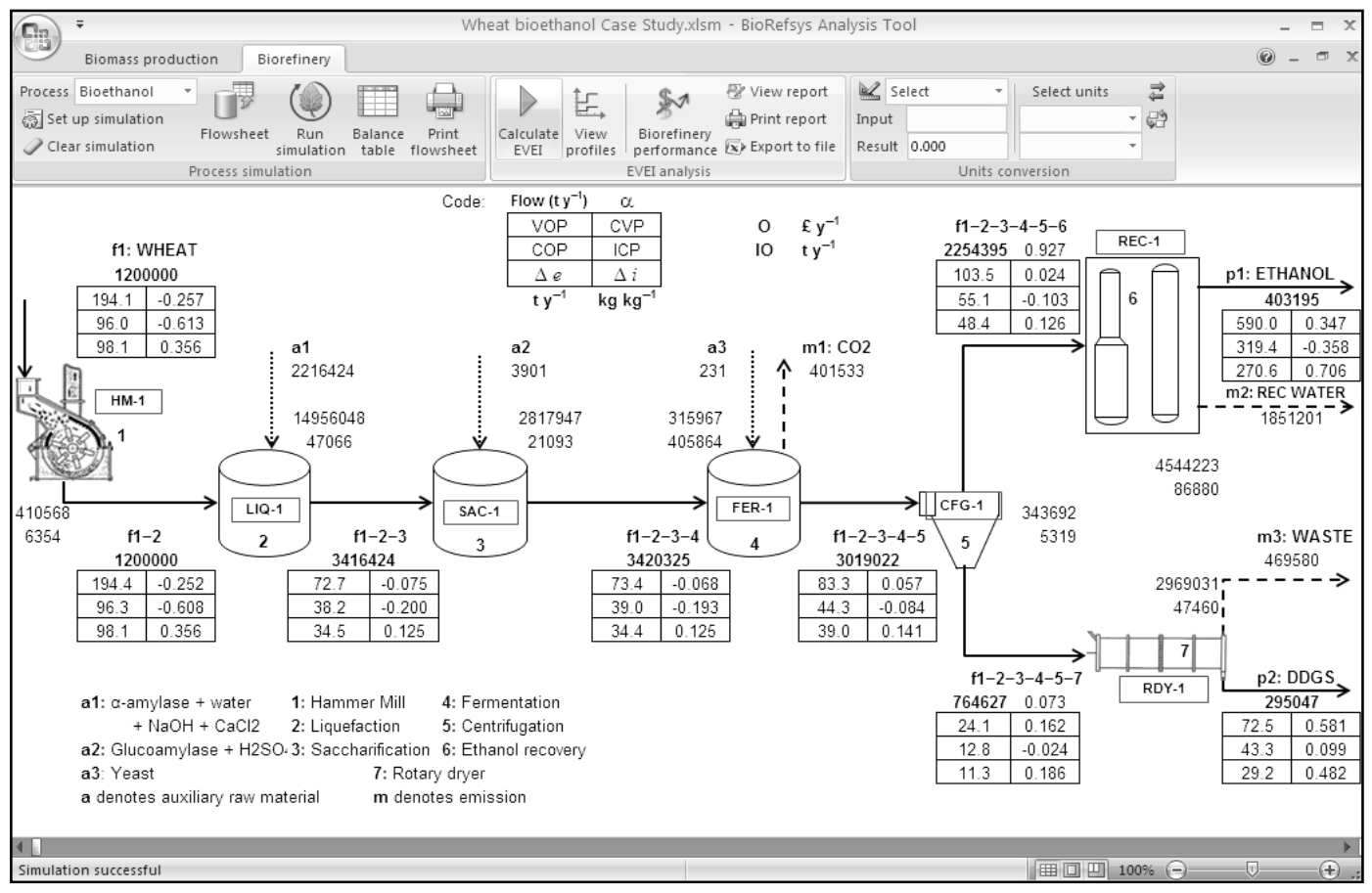

Fig. 7 


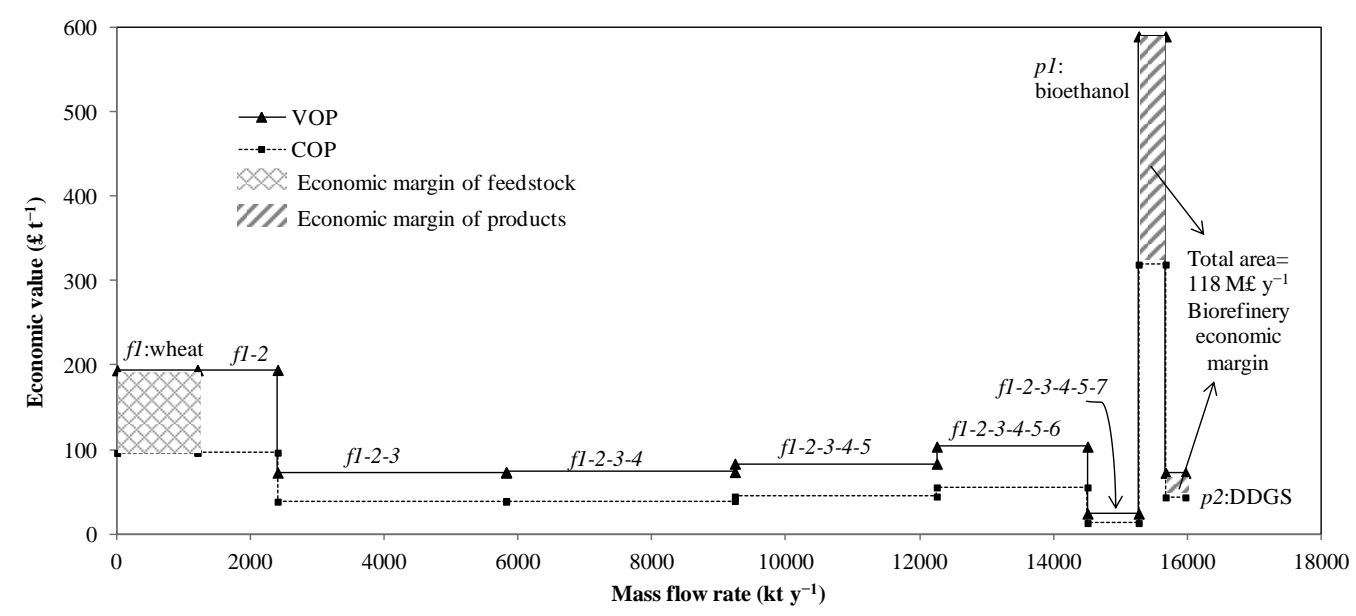

(a)

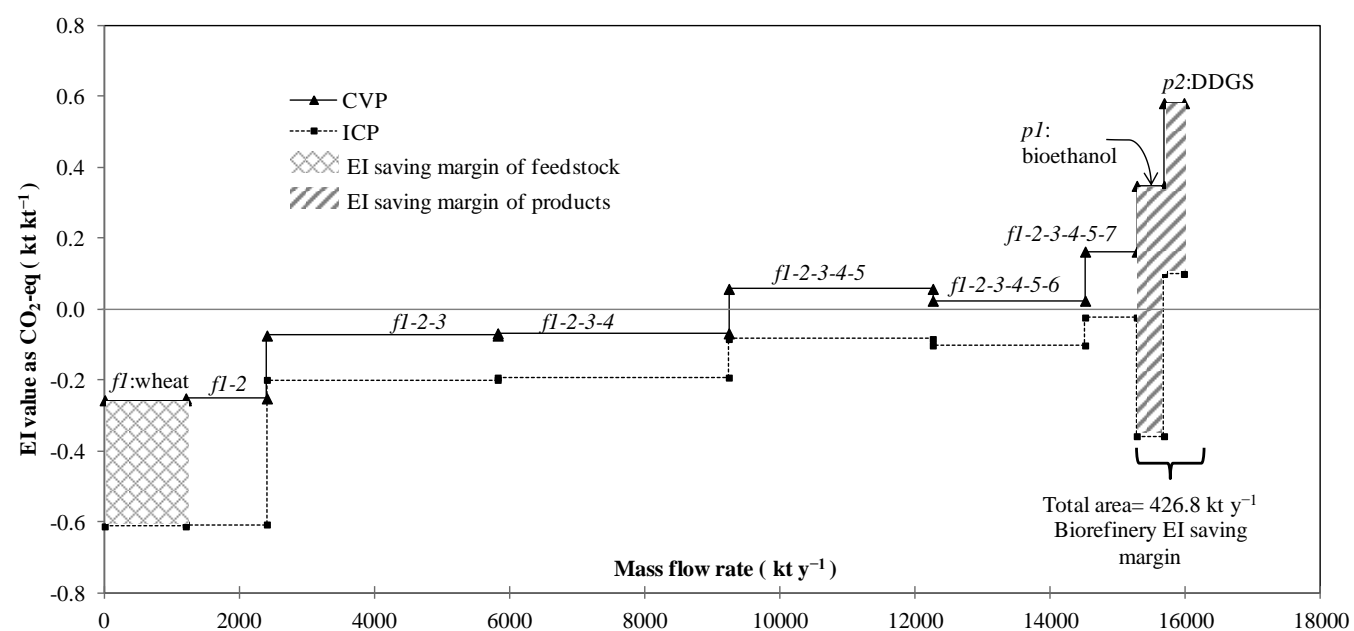

(b)

Fig. 8 
Table 3 Economic $\left(£ \mathrm{y}^{-1}\right)$ and $\mathrm{EI}\left(\mathrm{t}^{-1}\right.$ of $\mathrm{CO}_{2}$-eq) operating costs of the process units from the biorefinery in Fig. 3.

\begin{tabular}{ccrrrr}
\hline Unit & Costs & Utilities & $\begin{array}{c}\text { Auxiliary } \\
\text { raw } \\
\text { materials }\end{array}$ & $\begin{array}{c}\text { Emissions } \\
\text { /wastes }\end{array}$ & \multicolumn{1}{c}{ Total } \\
\hline 1 HM & $O$ & 410568 & & & 410568 \\
& $I O$ & 6354 & & & 6354 \\
2 LIQ & $O$ & 1876048 & 13080000 & & 14956048 \\
& $I O$ & 37749 & 9317 & 47066 \\
3 SAC & $O$ & 74719 & 2743228 & & 2817947 \\
& $I O$ & 477 & 20616 & & 21093 \\
4 FER & $O$ & 314811 & 1156 & & 315967 \\
& $I O$ & 2551 & 1780 & 401533 & 405864 \\
5 CFG & $O$ & 343692 & & & 343692 \\
& $I O$ & 5319 & & & 5319 \\
6 REC & $O$ & 4544223 & & & 4544223 \\
& $I O$ & 86880 & & & 86880 \\
7 RDY & $O$ & 2969031 & & & 2969031 \\
& $I O$ & 47460 & & & 47460 \\
\hline Total & $O$ & 10533093 & 15824384 & & 26357476 \\
& $I O$ & 186790 & 31713 & 401533 & 620037 \\
\hline
\end{tabular}


Table 4 Examples of EVEI analysis calculations.

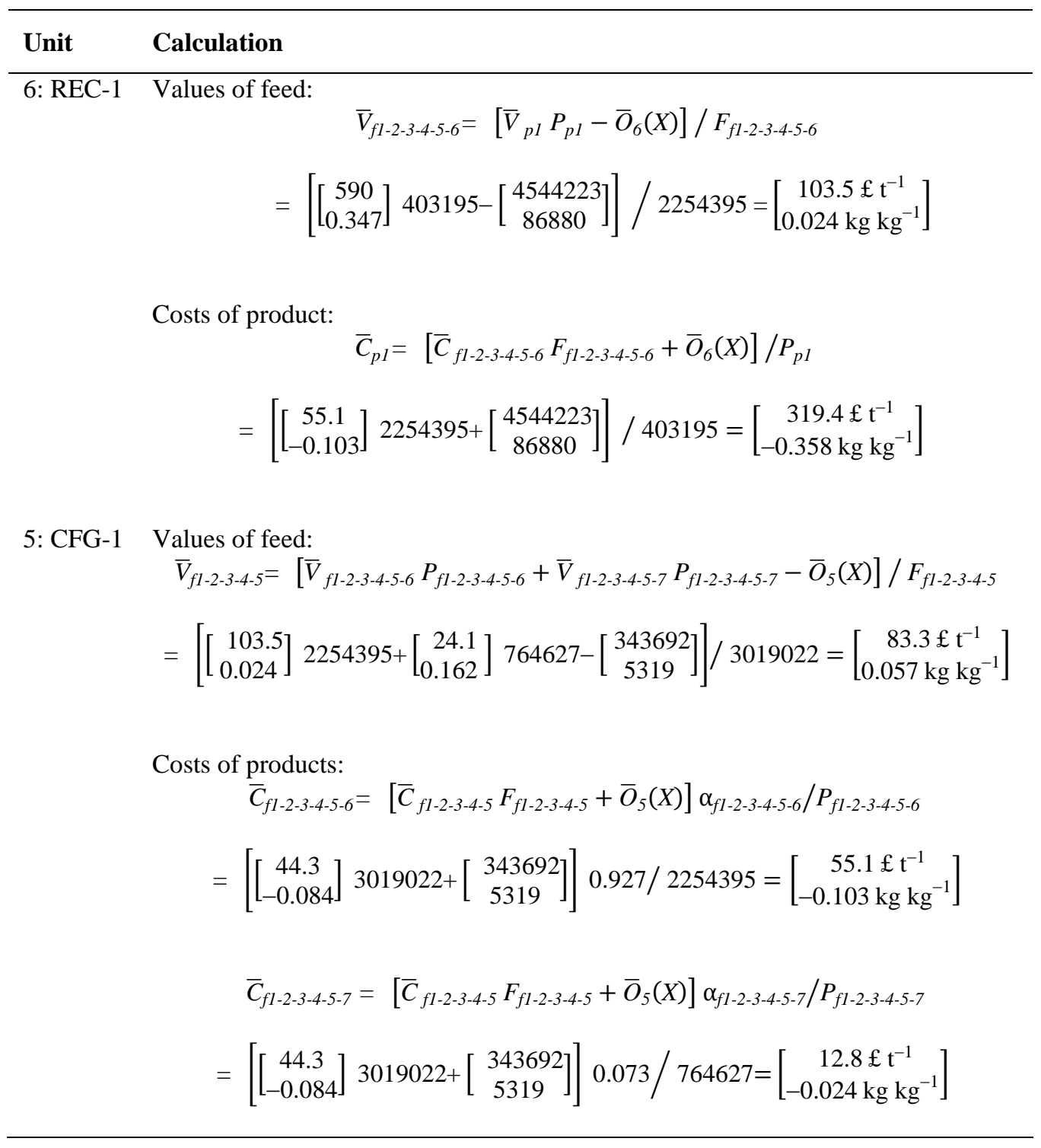

